\title{
Managing the collective intelligence of local communities for the sustainable utilisation of estuaries in the Eastern Cape, South Africa
}

\author{
Lucky N Mosia \\ KwaZulu-Natal Law Society Library \\ lucky@lawlibrary.co.za \\ Patrick Ngulube ${ }^{2}$ \\ Information Studies Programme, School of Sociology and Social Studies, \\ University of KwaZulu-Natal, (Pietermaritzburg) \\ ngulubep@ukzn.ac.za
}

\begin{abstract}
Received: 16th February 2004
Revised: $13^{\text {th }}$ April 2005

The aim of this study is to demonstrate that managing the collective intelligence of the community, that is, tacit and explicit knowledge is key to the sustainable utilisation of resources. Studies have shown that sharing knowledge is problematic in most organizations, whether they are formal or informal. In that regard, a study was conducted to determine how knowledge was shared and distributed in an "open" system such as the Tyolomnqa Estuary in the Eastern Cape. Secondary data was gathered from the existing literature, whereas questionnaires, interviews and focus groups were used to collect primary data. The study revealed that knowledge sharing among the communities using the Tyolomnqa Estuary was fragmented. A model to facilitate the sharing of knowledge on the management of estuaries in the Eastern Cape based on communities of practice and storytelling is suggested.
\end{abstract}

Keywords: Collective intelligence, knowledge management, knowledge sharing, estuaries, communities of practice, storytelling

\section{Introduction}

Studies have shown that knowledge sharing is a crucial process within an organisational setting, whether the setting is a formal working group or an informal community such as the one along the Tyolomnqa Estuary in the Eastern Cape Province of South Africa. Thus, the management of the collective intelligence of a community may facilitate knowledge transfer. It is widely recognised that knowledge sharing and distribution plays a central role in knowledge management (e.g. Probst, Raub \& Romhardt 2002: 198). Knowledge management is increasingly identified to be key to integrating and sharing the diversity of knowledge in a community that desires to achieve collective goals.

The research that was done recently in the communities with vested interests in the Tyolomnqa Estuary indicated that knowledge sharing was not an obvious practice despite the fact that knowledge is increasingly becoming a strategic resource that needs to be created and harnessed effectively in order to successfully utilise resources. Knowledge is often personalised and resides in pockets in communities within societies while effective and sustainable growth of a community requires integrating and sharing distributed knowledge.

In this article we have tried to disciss the concept of estuaries, knowledge, knowledge management, collective intelligence, knowledge sharing and knowledge sharing in closed and open systems. We have then turned to the case study used in the research before winding off by discussing the proposed model of knowledge sharing that may be adapted to serve the needs of estuaries in the Eastern Cape.

\section{Literature review}

Under this subheading we will discuss the concept of estuaries, knowledge, knowledge management, collective intelligence, knowledge sharing and knowledge sharing in closed and open systems.

Estuaries: places where rivers meet the sea

According to the Environmental Protection Agency (2003), "an estuary is a partially enclosed body of water formed where freshwater from rivers and streams flows into the ocean, mixing with the salty sea water". Estuaries are valued for their scenic beauty, recreation opportunities and their contribution to quality of life. Complex, dynamic and relatively fragile environments characterize estuaries, therefore, protecting them is essential if the natural resources they offer are to be maintained (Harrison, Cooper \& Ramm 2000). It would be important for estuary users to maximise their understanding and use of knowledge if the delicate balance of the estuarine ecosystem is to be sustained.

I. Lucky Mosia, who obtained her Masters degree in Information Studies at the University of KwaZulu Natal in 2004, is a librarian at the KwaZulu-Natal law Society Library

2. Patrick Ngulube (PhD), is a senior lecturer in the Information Studies Programme, School of Sociology and Social Studies, at the University of KwaZulu-Natal, Pietermaritzburg. 
Estuary managers and local users need access to information and knowledge in order to understand and participate in the process of managing estuary resources. The increasing need for improved estuarine management dictates that stakeholders should collaborate and share knowledge. The system of linking these stakeholders' knowledge and information is very weak in South Africa (Maponya 2003). However, there is a growing awareness of the need to develop more consistent and better means of sharing information and knowledge on estuaries.

Knowledge, knowledge management and collective intelligence

Harnessing the power of knowledge depends on knowing what it is and what it is not (Huseman \& Goodman 1999:103). According to Knight and Howes (2003:18) the commonly accepted definition of knowledge, which goes beyond the western systems of thought, is as follows:

Knowledge is the whole body of cognition and skills which individuals use to solve problems. It includes both theories and practical, everyday rules and instructions for action. Knowledge is based on data and information, but unlike these, it is always bound to persons. It is constructed by individuals, and represents their benefit about causal relationships (Probst, Raub \& Romhardt 2000: 24):

Although, there is no agreed definition of knowledge management we tend to agree with Todd (I999:II) that the process of organising and leveraging knowledge embedded in people's experiences, competencies, talents, ideas, practices, intuitions, skills, wisdom and capabilities, in addition to documented and codified sources may be characterised as knowledge management. The definition accommodates tacit knowledge that is embedded in people's minds and explicit knowledge which is represented in various documents and formats.

Put differently, knowledge management is the process of capturing people's collective intelligence or experience, whether it resides in documents, databases or in people's heads (Hibbard 1997). However, collective intelligence is not a new concept. One of the earliest references to the phrase "collective intelligence" is in Hawken, Ogilvy and Schwartz (1980:9). To Hamilton (2004) collective intelligence is a phenomenon that until recently has almost escaped the lens of the social sciences.

Many definitions of collective intelligence exist. For instance, the Co-Intelligent Institute (2003) identified seventeen definitions of collective intelligence available online. The definition that is used in this paper is by Noubel (2003) who defined collective intelligence as:

$\ldots$ the oldest human social organization where individuals decide to mutualize their knowledge, know-how

and experience in order to generate a higher individual and collective benefit than if they remained alone.

It is evident from the definition that collaboration and sharing are keys to sustaining collective intelligence. The assumption is that people can do more together than they could do alone. Knowledge management processes can facilitate the integration of tacit and explicit in order to promote the use of society's collective intelligence. The major challenge is designing strategies of putting both tacit and explicit knowledge into action by creating context and infrastructure that facilitate the location and use of the collective intelligence of communities (Robertson 2003).

Knowledge sharing

Although it is generally believed that "knowledge is power", knowledge does not become powerful until it is shared (Robertson 2003). According to Robertson (2003), knowledge in an organisation increases when it is shared. Knowledge can be shared by making information easily available through technology, by holding knowledge sharing sessions among communities of practice and storytelling as described in the subsequent sections of this article.

The social interaction of people facilitates the generation and sharing of knowledge. Knowledge sharing and distribution is key to the success of social reengineering processes. Knowledge sharing leads to improvement of processes and innovation. It is vital that knowledge should be shared and distributed in all human environments. Knowledge sharing should not be restricted to "closed" business systems with formal structures. It can also be practised in open systems or in "the wild" as expressed by Hutchins (1995). Although open systems are composed of different stakeholders with different organizational allegiances, isolated information, experiences, skills and know-how can be harnessed for the sustainable utilization of resources (Mosia 2003). Now let's turn to knowledge sharing in both closed and open systems.

Knowledge sharing in closed and open systems

Closed systems or formal organizations are structured business enterprises such as universities, banks, schools, and law firms. They have specific rules, structures, missions and goals to which members of the organizations subscribe. They also have formal structures and rules that govern operations. Knowledge sharing in such environments is likely to be easier than in the informal systems. The integration and coordination of the members of a group is fairly easy in closed environments. Thus capturing what the other members of the group already know and adding one's own knowledge becomes faster and more efficient in such systems than in open ones. 
On the other hand, an open system or what Hutchins (1995:370) referred to as the "wild" brings together persons from different organizations and sectors of community. People work in collaboration with one another in the short term. Although certain activities may bring stakeholders together, the rules, regulations and structures that govern the system and its operations are not "rigid" and are at times informal. Therefore, in open systems members or different stakeholders often work individually and have formal allegiances elsewhere (Denning 2000). In the case of the Eastern Cape Estuaries, the stakeholders include national, provincial and local government, estuary forums and communities living along the estuary, to mention a few. The local communities living along the estuaries do not have structures to coordinate their collective intelligence on the management of estuaries (Breen et al., 2004).

\section{Knowledge sharing in the Eastern Cape Tyolomnqa Estuary}

The case study presented in this paper is based on the Eastern Cape Management Programme (ECMP) that was initiated by the Institute of Natural Resources in the middle of 1998. The Eastern Cape Estuary Management Programme (ECEMP) consisted of a group of researches and policy makers. The researchers were working in collaboration with one another. However, they were responsible for conducting different researches on the management of the estuaries addressing different areas, namely governance, biodiversity, sustainability, monitoring, rehabilitation, co-operative management systems and knowledge management.

As researchers concerned with knowledge management we carried out a study to determine the optimal means of knowledge sharing and distribution in an "open" system using the Eastern Cape Tyolomnqa Estuary as a case study. To some extent, our research methodology was similar to action research in the sense that we attempted to produce results of practical value to estuary users while at the same time adding to theoretical knowledge and gaining expertise.

We found the case study approach suitable because case studies are appropriate for studies which aim to provide an in-depth description of a small number of cases within their real life context (Mouton 200 I:I49; Yin 1994: I 3). This study arose from the proposition that knowledge sharing was not an obvious practice among the Eastern Cape Estuaries communities. In order to confirm or refute such a proposition it would be necessary to gather empirical evidence from a number of estuaries on how they manage their collective intelligence.

The communities living along each individual estuary would be a case from which the required empirical evidence would be gathered. If it can be shown that the majority of cases are not effectively sharing their knowledge, then the proposition will confirm Rowley's idea that:

The method of generalisation for case studies is not statistical generalisation, but analytical generalisation in which a previously developed theory is used as a template with which to compare the empirical results of the case study. If two or more cases are shown to support the same theory, replication can be claimed... The greater the number of case studies that show replication the greater the rigour with which a theory has been established (Rowley 2002:20).

Thus, the information that was obtained by this research may be used towards building a database of information which, together with other cases, will confirm or refute the case. According to Rowley (2002:21), "the more cases that can be marshalled to establish or refute a theory the more robust the research outcomes".

\section{Procedure and data collection methods}

The empirical part of the study derived data from a variety of sources. The use of more than "one source of data, more than one method of data analysis, more than one researcher, and more than one perspective" is called triangulation (Botes 2003:18I). Triangulation, if used appropriately can enhance the validity of research results. In that regard, semistructured interviews, focus group discussions, questionnaires, and the literature were used to collect data by the two researchers. The use of questionnaires in conjunction with interviews was identified as useful methods of gathering data on knowledge management activities in organisations (Webb 1998:22).

Semi-structured tape recorded interviews were conducted with 16 people who were purposively selected due to their involvement in the management of estuaries in the Eastern Cape. They included stakeholders from the Buffalo City Council, Tyolomnqa Conservancy, Tyolomnqa Estates, Tyolomnqa Forum and the members of the local communities such as Phozi, Ncera, Sandile and Xhama. The key informants were people with management positions, and community leaders living along the estuary. Respondents were asked seven basic questions:

I.What challenges do you encounter in the use and management of the Tyolomnqa Estuary?

2.What strategies do you use to deal with the challenges?

3.What sources of information do you use to get information on the management of estuaries?

4.What methods and techniques do you use to share and distribute knowledge?

5.Are there any human factors that hinder knowledge sharing and distribution?

SA Jnl Libs \& Info Sci 2005, 7 I (2) 
6. How effective and efficient are current methods of knowledge sharing and distribution?

7.Which information and technology tools can be used in sharing and distributing knowledge in the Tyolomnqa Estuary?

Focus group interviews were held with members of the Tyolomnqa Forum and the Phozi, Ncera, Sandile and Xhama communities. Having gained significant popularity among market researckers, focus groups are becoming widely used by information professionals to gather data on group norms and shared experiences (vor: Seggern \&Young 2003:272). However, focus groups are frequently used as an adjunct to other methods (Barbour \& Kitzinger 1999:6; Bloor et al., 200 I:8; Caineron 2000:87; McClelland 1994:29). That partly explains why this study used them in conjunction with other methods.

The literature provides guidelines for the use of focus group in social science research (Bloor et al., 200I; Krueger 1994). However, studies are not agreed on the size of focus groups. Orthodoxy market research literature recommends a size of between 8 and 12 (Barbour \& Kitzinger 1999:8). Table I summarizes selected optimal focus group sizes found in the literature in order to demonstrate the varying sizes of groups the researchers are likely to find in the literature.

Table I Optimal focus group sizes found in the literature

\begin{tabular}{ll}
\hline Author(s) & Optimal focus group size \\
\hline Bless \& Higson-Smith (2000:110) & $4-8$ \\
Bloor et al., (2001:26) & $6-8$ \\
Cameron (2000:84) & $6-10$ \\
McClelland (1994:29) & $8-12$ \\
Stewart \& Shamdasani (1990:53) & $6-12$ \\
von Seggern \&Young (2003:274) & $4-12$ \\
\hline
\end{tabular}

The size of the groups used by Green and Hart (1999:22) ranged from three to thirteen. Kitzinger (1994:161) had an average of six participants in each of the fifty-two groups involved her AIDS project. Gloet $(2002: 312)$ used two focus groups composed of 26 and 3 I participants. On the other hand, Hellström and Husted (2004:17I) used 27 participants in their focus group discussions. Uitimately,

the size of the group should manifestly be governed by two considerations...it should not be so large as to be unwieldy or to preclude adequate participation by most members nor should it be so small that it fails to provide substantially greater coverage than that of an interview with one individual (Merton, Fiske, \& Kendall 1990:137).

In fact, Barbour and Kitzinger (1999:I) cautioned researchers against using "formulaic approach" advocated by market researchers in determining the size of focus groups.

The number of groups that should be convened depends on the composition of the group and the aims of the research. However, Morgan (1988) observed that one group is never enough. In that light, we had five different discussions with groups made up of twelve respondents from the Tyolomnqa Forum, six from Phozi Village, ten from Ncera Village, eight from Sandile Village, and twelve from Xhama Village. The sizes of the groups were dictated by logistical considerations and the willingness of the participants to be involved. Focus groups were conducted to obtain specific types of information from clearly identified individuals.

The second author introduced the topic for discussion and then invited and moderated discussions from the groups. The discussions were tape-recorded and notes were recorcied on flip chart and a summary of each meeting was given before the members of the group dispersed. The topics weres tructured around inierview questions outlined above. Discussions around each question lasted for 20 to 30 minutes. Lunch and refreshments were provided for the participants.

A self-administered questionnaire was chosen as another data collection instrument in the present study. The questionnaire contained closed and open-ended items. It was first pretested using a convenience sample before it was used in the study. It was used to collect data from I 4 researchers involved in the ECEMP. It was distributed and collected during the proceedings of the workshop that took place in Port Elizabeth, in the Eastern Cape in October 2002. This was done because it provided an opportunity to get the data quickly from the core group of researchers involved in the ECEMP. Researchers were asked 22 questions each to determine the means and methods they used to share and transfer knowledge on the management of estuaries.

When it came to data analysis, tapes from semi-structured interviews and focus group discussions were transcribed and coded. The analysis of focus group data was guided by the analysis strategies identified by Krueger (1994: 143- 144): transcript-based analysis, tape-based analysis, note-based analysis and memory-based analysis. In that regard, field notes and transcripts were content analysed. The use of these analysis strategies yielded data that was combined with data from 
semi-structured interviews. The results from qualitative data are presented in "impressionistic rather than numerical terms" (Cameron 2000:99). Data collected by means of questionnaires were analysed through content analysis and the use of SPSS, and presented descriptively and in the form of tables and figures.

\section{Results and discussions}

This section presents the major findings. The findings are divided into two sections. We present the results of interviews and focus group discussions before turning to the results of the questionnaires administered on the researchers.

5.1. Results of interviews and focus group discussions with local community members

The majority of the informants were male. The selection of respondents was not predetermined by the researchers, but was caused by natural selection. More men appeared to be involved in estuarine related activities than women in the Tyolomnqa area. The informants had different views on what could be done to develop and sustain the estuary. They got most of the information on how to use and preserve the estuary from informal contacts with colleagues and meetings. The explicit knowledge on the management of estuaries contained in documents and databases was not easily accessible to the informants due to literacy, language and technological barriers. Equally, the use of knowledge from central and provincial government was very limited.

It was evident that in spite of having ideas about the management of estuaries, they also did not have enough knowledge on how to deal with some of their concerns. Some of their major concerns in relation to the management of their estuary are summarized in Table 2.

Table 2 Challenges faced by the Tyolomnqa Estuary users

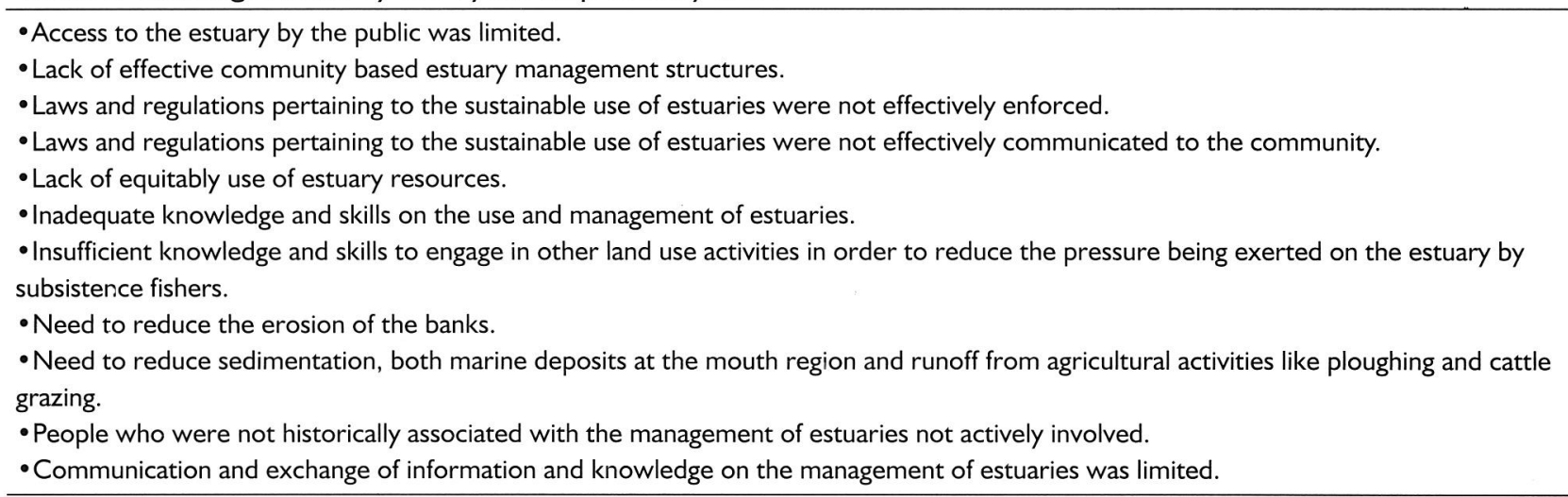

Limited means and resources for sharing and distributing knowledge caused most of the problems outlined in Table 2. The stakeholders living along the estuary also functioned like rivals and that naturally compromised the sustainable use of the estuary resources. They did not have a culture of knowledge sharing. In a survey of 412 designated representatives of Best Practice Club $^{\text {TM }}$ orgarizations, Chase (1997: 46) discovered that $80 \%$ of the respondents regarded organizational culture as the biggest obstacle to creating a knowledge-based environment.

One of the key objectives of this study was to identify the existing methods and techniques for knowledge distribution and sharing among local communities. The reason for this was to enable the researchers to have an impressionistic view of the effectiveness of the methods that were available, choose from the good ones, make suggestions on improving the poor ones and suggest other methods and techniques. Semi-interviews and focus group discussions revealed that the main means of sharing information and knowledge among local villagers were person-to-person communication, community meetings, general meetings, workshops, messages passed through school children during announcements at school assemblies and writing letters.

Although the informants indicated different kinds of methods that they used for disseminating information and knowledge, they did not specify the kind of knowledge or information that is suited for each specific technique. However, based on our knowledge from the existing literature of information use or adoption process for example, it is possible to predict or speculate what kind of delivery system or technique is appropriate for specific information and knowledge need levels. For example, we know that in cases where people simply need to be made aware of something, mass communication or mass meetings are sufficient to convey the necessary awareness messages. However, in instances where people have to learn particular skills or assimilate specific know-how, one-on-one or personal interaction is most appropriate.

While face-to-face delivery of information and knowledge are appropriate and effective in some situations and for delivering specific types of knowledge, it may not be appropriate in all cases. Some of the problems with face-to-face techniques include the slowness at which knowledge is delivered. It also means that at times only a few people can be 
communicated to at a given time. Therefore, even though village members distributed and shared knowledge in their own ways, the methods available were not always and in all cases as effective and appropriate as the one used by informants from the Buffalo City Council, Chalumna Estate and Tyolomnqa Conservancy as well as ECEMP researchers who had access to computers, telephone and faxes, not only in their working places but in their homes as well.

According to Abell and Oxbrow (200I:5I) information and communication technologies (ICTs) are key enablers of the knowledge environment. Technology facilitates the process of transmitting and exchanging information. Responses from the interviews and focus groups demonstrated that local villagers had limited access to personal telephones, faxes, computers and other modern communication means. There appeared to be only one public telephone in each of the villages that were included in the study. They mostly relied on individuals' telephones when sharing urgent knowledge. Limited access to ICTs in the villages created a barrier and a delay in distribution and sharing of knowledge amongst the estuary users. As much as the importance of ICTs has been stated, the study revealed that ICTs infrastructure along the Tyolomnqa Estuary was grossly inadequate.

The situation among villagers in the Tyolomnqa area is not very different from that of other villagers in rural South Africa in particular and Africa in general (Levey \& Young 2002). However, it is important to address their problems based on the potential usage of technology that is increasingly becoming available. For example, steel sided kiosks equipped with computers have been introduced into some villagers in Cwili near Kei Mouth (Philp 2003:10). Although the project was designed by the Council of Scientific and Industrial Research with the support of the Department of Science and Technology to find out whether rural South African children had the cognitive skills to understand computers without any formal training, it shows that the technology model of sharing and distributing knowledge among the rural communities in South Africa is feasible.

It also emerged from the interviews and discussions that the Tyolomnqa Forum was also used as a means of sharing knowledge but the Forum meetings were held once in a while and some of the representatives did not enjoy a lot of support from the communities that they were drawn from. The Tyolomnqa Forum comprised people who had vested interests in the management of the Tyolomnqa Estuary. It appeared to be the most viable means that can be used to share and distribute knowledge in situations like we have in the Tyolomnqa Estuary where there is no organizational structure to bring together people to share knowledge.

\subsection{Results of the survey by questionnaire of the ECEMP researchers}

Twelve questionnaires were completed and returned. The response rate to the questionnaire was affected by the fact that not all the 14 researchers that were targeted by the study attended the workshop where the questionnaire was distributed. In addition, the two researchers from one sub-programme who failed to attend the meeting did not respond to the questionnaires sent to them through the postal and electronic mail systems. The respondents of the selfadministered questionnaire were balanced between the two genders unlike the case with interviews where male informants dominated.

The methods used by researchers for knowledge sharing and distribution are illustrated in Table 3.

Table 3 Methods used for knowledge sharing and distribution

\begin{tabular}{ll}
\hline Methods used & Number of respondents using method \\
\hline Face-to-face & 12 \\
E-mail & 10 \\
Informal contact with colleagues & 8 \\
Written documents & 7 \\
Internet & 7 \\
Technical manuals & 7 \\
Intranet & 6 \\
Workshops and seminars & 5 \\
Brochures & 2 \\
\hline
\end{tabular}

There were multiple responses to options given in the questionnaire. Judging by the number of responses presented in Table 3, there were various methods used by the researchers on the ECEMP for knowledge sharing and knowledge distribution. Like in the case of the communities living along the Tyolomnqa Estuary, face-to-face communications seem to dominate their mode of knowledge sharing and distribution. However, the researchers utilized information and communication technologies (ICTs) more than the communities living along the estuary.

The respondents identified some barriers that affected knowledge sharing and distribution and the results are summarized in Figurel. 


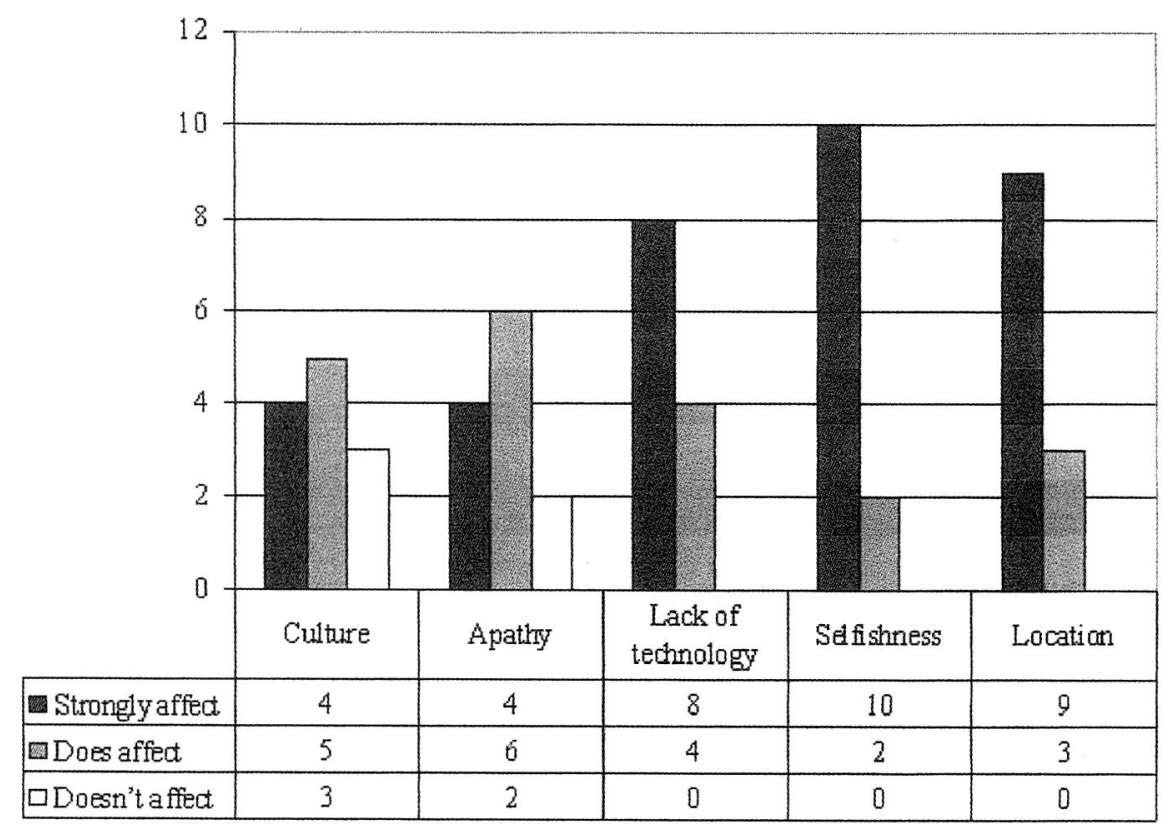

Figure I Barriers to knowledge sharing and distribution

Judging by the number of responses in Figure I, it shows that respondents believed that selfishness was the major barrier to knowledge sharing and distribution, followed by location of the individual in relation to others, and then lack of technology. The majority of respondents agreed that apathy and culture might be some of the barriers to knowledge transfer. Research has shown that creating a knowledge sharing culture is fundamental to knowledge transfer. Research carried out by Skyrme and Amidon (1997) revealed that, "the greatest inhibitor to knowledge sharing was inappropriate behaviours and organisational culture".

It was discovered that unlike most of the communities along the Tyolomnqa Estuary, ECEMP researchers had various ICTs at their disposal. Table 4 gives as summary of the ICTs that were at their disposal. The results presented in Table 3 suggest that the level of utilization of these ICTs by researchers was rather limited. However, their level of use of ICTs was not comparable to the disadvantaged communities living along the Tyolomnqa Estuary.

Table 4 Type of information and communication technologies accessible to ECEMP researchers

\begin{tabular}{ll}
\hline Information and communication technology & Respondents using methods \\
\hline Computers & 12 \\
Telephones & 12 \\
Cell phones & 7 \\
E-mail & 12 \\
Internet & 7 \\
Intranet & 5 \\
Fax machines & 12 \\
Radio & 5 \\
Video conferencing & 1 \\
\hline
\end{tabular}

\section{Conclusions}

This study has found that the knowledge sharing activities of the communities living along the Tyolomnqa Estuary were fragmented. ECEMP researchers and the communities living along the Estuary mainly used informal and face-to-face contacts to share and transfer knowledge. Communities living along the Estuary had limited access to explicit knowledge on the management of estuaries contained in documents and databases. That implies that, in spite of the fact that the local community had ideas about managing estuaries and provided some suggestions of estuary development and their successful maintenance, but they had some knowledge gaps.

It is clear from the findings that although stakeholders attained and owned knowledge there were limitations in distributing and sharing it. The use of mass meetings noted by the study is mainly effective for awareness of ideas and does not provide means for effective understanding and learning. Face-to-face interaction provides a good understanding of knowledge to be shared; however, it is slow and requires a lot of time of interaction for it to be effective. 
There were no established formal structures along the Tyolomnqa Estuary to facilitate the sharing of knowledge as one would find in bureaucratic organizations like companies. However, organisational structures are key to facilitating knowledge sharing (Robertson 2003).

As part of recommendations, the structures described in the following texts may facilitate the sharing of the collective intelligence of the communities living along the Tyolomnqa Estuary. The model may be adapted to other estuaries in the Eastern Cape.

6.1 Organisational structures to facilitate knowledge sharing in an open system

Collaboration and sharing of knowledge in open systems as the Tyolomnqa Estuary tend to be very limited. As Hutchins (1995:198) argued, "there is no communication between the active agents other than their effects on a shared environment. Each agent simply mills about taking action only when he encounters situations on which he can act". The interconnection systems of such an environment are loose and know!ledge is distributed among different actors and embedded in various artefacts (Hutchins 1995:220).

According to Robertson (2003) it is important to have some kind of organizational structure in order to facilitate knowledge sharing organisations. The Tyolomnqa Estuary Forum, which has vested interests in estuary management, may be used as a model to provide the organisational infrastructure to facilitate the acquisition and sharing of knowledge on the management of estuaries among estuary users and managers, and other people involved.

The estuary management forum would be linked to the Integrated Development Planning Department within coastal municipalities. In that regard, the model that is suggested should be implemented with the framework of the Integrated Development Planning Department within coastal municipalities. Municipalities are likely to have the prerequisite resources to provide the knowledge management infrastructure as compared with the local relatively disadvantaged communities.

According to the Municipal Systems Act No 32 of 2000 every municipality must work out and adopt a development plan for areas under its jurisdiction. For this reason local municipalities would develop plans that incorporate estuaries so that the development in and around estuaries would be related to the goals of the municipality (Breen et al., 2004; Mosia \& Ngulube 2003). The department responsible for the integrated planning process in the municipality would act as a knowledge centre or repository. The department would create knowledge pools at estuary level and foster knowledge sharing. The proposed organisational model is illustrated in Figure 2.

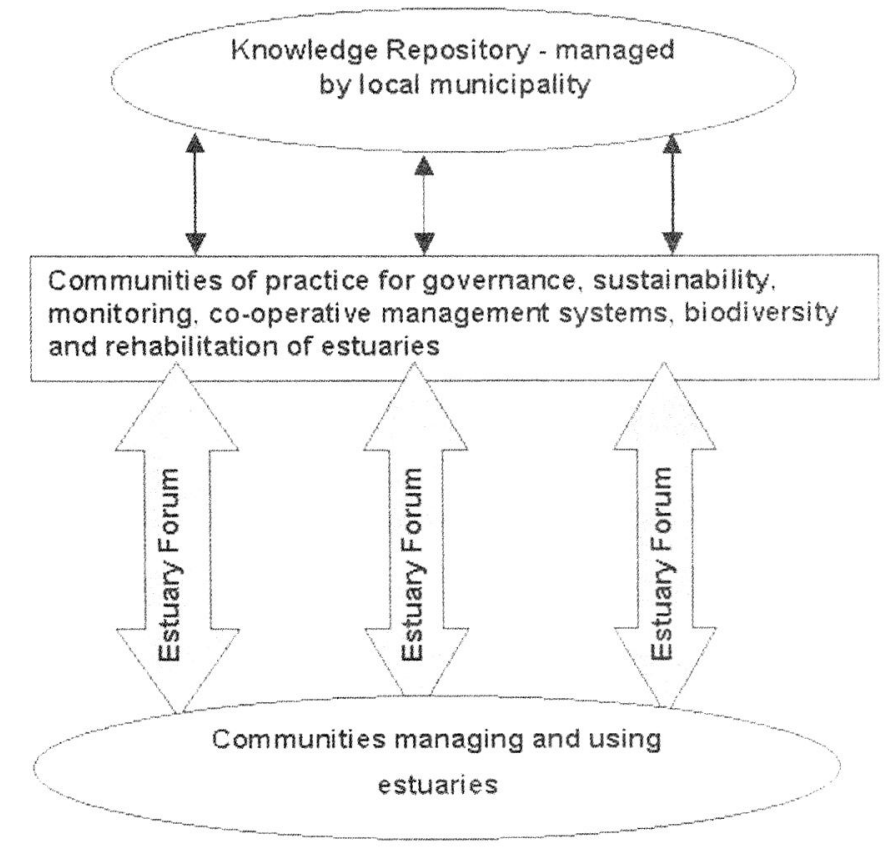

Figure 2 Proposed organisational infrastructure for sharing estuary knowledge

It should be made clear from the onset that the knowledge repository is not supposed to store knowledge, but it should be able to direct users to knowledge sources. For instance, yellow pages in a telephone directory direct users to the goods and services provided by subscribers rather than the actual resources. 
The implementation of this model will largely depends on the estuary forum utilizing knowledge sharing techniques and methodologies such as storytelling and communities of practice. Through the estuary forum, the "outside" technical experts like researchers could also participate and share their knowledge. The following sections discuss how communities of practice, storytelling and information and communication technologies may be used to develop a culture of knowledge sharing among estuary users. Communities of practice and storytelling as means of knowledge transfer are suitable for the communities under study because they have a tradition of face-to-face interactions and informal interactions. However, for these strategies to be effective there is a need to work through an organisational structure as suggested in Figure 2.

\subsection{Developing and implementing the knowledge sharing culture}

The culture of knowledge sharing may be developed, implemented and practised through the use of technology, holding knowledge sharing sessions among communities of practice and storytelling. Storytelling has the pctential to build positive relations in communities. As communities of practice, storytelling may facilitate the location and use of the collective intelligence of communities. On the other hand, information and communication technologies add icing to the cake by facilitating the use and sharing of the collective intelligence.

\section{Information and communication technology as an enabler of knowledge sharing}

The use of information and communication technologies (ICTs) may enable knowledge sharing. Internet-based webs, groupware and data warehousing were the tools that were used most in managing knowledge repositories in many organisations (Alavi \& Leidner 1999; Awad \&Ghaziri 2004; Davenport \& Prusak 1998). Intranets can increase the volume of electronic and organisational communications as well as supporting group collaboration.

However, the utilisation of ICTs is not a pariacea for all knowledge sharing and exchange initiatives. Choo, Detlor and Turnbull (2000:37) pointed out that, "The most advanced computer-based information systems on their own cannot generate new knowledge". To Wiig (1999) ICTs "can only provide us with rudimentary reasoning devoid of innovation and with concrete analyses of the past through approaches such as knowledge discovery". According to Chase (2002:22) and Gamble and Blackwell (200I:163), technology facilitates information flow and enables performance.

Experience from elsewhere shows that while iCTs are important in facilitating interaction between the knowledge leaders, they cannot surpass the dynamics of face-to-face meetings (Storck \& Hill 2000:73). Our own experience with the ECEMP research sub-programme's listserv or discussion group seems to support the point raised by Storck and Hill (2000). During the first phase of the project the knowledge management team set up a listserv in order to facilitate collaboration between researchers.

Only five out of the 14 researchers involved in the ECEMP's seven sub-projects joined the listserv despite having the enabling technologies and being implored to do so by the funders of the project. The five researchers came from three sub-projects. Only three of these researchers contributed to the group's discussions. This mode of collaboration was discontinued as it was found to be ineffective where projects were supposed to share experiences.

The reason for the failure of the listserv may be that the researchers on the programme did not have a common organisational structure as they came from various research institutions in South Africa and perhaps, they did not have mutual interests other than the contractual obligation to the project. Digital interaction is not likely to succeed if openness and mutual trust is not promoted first. Trust and not technology is key to creating and sharing knowledge (Awad \& Ghaziri 2004; Newell et al., 2002).

Therefore, the availability of ICTs themselves without trust and appropriate skills among users does not lead to effective usage. Furthermore, the content of information (converted knowledge) to be transferred between the different users need to be appropriate. The ICTs should be appropriate, for example, the use of touch screens may enhance knowledge utilisation in rural settings. It is useless to simply pile ICTs in the rural community such as the one described in this paper with the highly sophisticated technical information, which is written in English and expect that it will assist local people who are semi-literate. As Hutchins (1995:230) observed, language may constrain the "cognitive properties of a group". In that regard, Snowden (2002) noted that context, narrative and content management rather than technology are likely to dominate future knowledge management initiatives. In that light, the model that is presented here emphasises more on communities of practice and storytelling than technology as tools for knowledge integration, transfer and sharing.

\section{Communities of practice}

In the previous section we outlined the importance and limitations of ICTs in relation to knowledge sharing. ICTs are best suited for connecting communities, but there are not very effective when it comes to knowledge transfer (Newell et al., 2002:131; Probst, Raub \& Romhardt 2002:150). Since knowledge is embodied, embedded, embroiled, encultured and encoded, to use Blackler's (1995) terms, in society its transfer is largely through social interaction and learning among 
communities. Communities of practice may facilitate learning and knowledge transfer among its members through storytelling and social networks.

Communities of practice are important analytic tools for understanding learning and knowledge (Roth 1999:16). Communities of practice are characterised by groups of like-minded people who regularly work together, developing collective knowledge and shared "sense making" of what they do and how they do it (Weick 1979). Thus, people who need to share and communicate ideas and expertise, and to solve problems can form communities of practice. Wenger (1998) and Gamble and Blackwell (2001:80) characterised knowledge communities as people:

- with a common purpose and shared vision;

- bound together by relationships of mutual engagement; and

- with a shared understanding of their situation including past experiences.

Members of the community of practice who share the same vision would know what is to be done and why it should be done (Wenger 1998:8I). It is evident from the interviews and focus group discussions that the communities with vested interest in the Tyolomnqa Estuary share the same vision about the need to preserve and maintain the estuary in a sustainable way. A shared vision is the basis for coherence for a community of practice. Mutual relationships and partnerships help the communities of practice to identify the areas where expertise lies. According to Wenger (1998:95) a shared understanding of their situation entails agreeing on the meaning of concepts, adopting common tools, telling and retelling stories and having the same styles.

According to Sallis and Jones (2002:26), "knowledge communities are probably one of the best practical means of developing and leveraging tacit knowledge, and many commentators see them as a way forward". In that regard, communities living along the Tyolomnqa Estuary may use communities of practices to harness and share the knowledge on estuary management that is stored in various repositories. In addition to social networking and storytelling, communities of practice may facilitate access to documents and information on best practices already created by others which these researchers found to be generally inaccessible to many informants who participated in this study.

Story telling

The increasing use of storytelling as a means of transferring and sharing knowledge further demonstrate the limits of technology for managing knowledge (Newell et al., 2002:I3I). The role of narratives in shaping knowledge is very critical because "for any knowledge to be meaningful it must be placed in the context of a story" (Balcomb 2000:5I). Balcomb (2000:5I) further posited that no facts or evidence, propositions and systems of belief have meaning unless they are chronicled in the context of a story. Stories have been used for thousands of years to connect people with nature (Donaldson 2003:3).

Storytelling and narratives are fundamental to our knowledge acquisition and transfer because: "We dream in narrative, daydream in narrative, remember, anticipate, despair, believe, doubt, plan, revise, criticise, construct, gossip, learn, hate and love by narrative" (Hardy 1975:4). Storytelling is fundamental to human experience and thinking (Balcomb 2000:61). It is no wonder that Appiah (1991) characterised storytelling as the village library. Storytelling supports communal forms of memory and reflection. Storytelling also plays a major role in decision-making (Jordan 1989:935). To Donaldson (2003:3), "Stories are natural and traditional, and can be used in many different ways - to reveal hidden knowledge assets, to transfer experience, and to build relationships". Put differently, narratives partly constitute the collective intelligence of communities.

People who live along estuaries could be brought together over coffee or even workshops and meetings to share their experiences as means of knowledge acquisition and transfer. Conversations and stories could help to solve difficult and problematic cases through sharing knowledge about their experiences with similar situations (Gamble \& Blackwell 200 I:40; Mosia \& Ngulube 2003). Thus, in the event of a problem, members of the community may tell each other about their past experiences in providing solutions to similar cases. The merits and demerits of the problem would be decided on the basis of the collaborative stories told by the community. In such situations, the stories constitute an important key to decision-making. According to Jordan (1989:935) such stories are:

packages of situated knowledge.... To acquire a store of appropriate stories and, even more importantly, to know what are appropriate occasions for telling them, is then part of what it means to be a member of the community of practice. (italics ours).

Storytelling can assist members of a community of practice to develop a common language and to use common terms that are appropriate to specific situations. Newcomers may be initiated and integrated into the community of practice through sharing stories, jokes and anecdotes. Newcomers become legitimate participants in the community of practice after gaining contextually relevant knowledge. Their knowledge may be accepted and validated by the community through their testimonies. Some testimonies may be challenged to the extent that they may have to be reconstructed. 
Thus, knowledge could be developed and shared through telling and comparing each other's stories as a community of practice.

Knowledge sharing needs to be developed implemented and practised through organisational structures of estuary management forums that would be linked to the Integrated Development Planning Department within coastal municipalities. Such organisational arrangement may help estuary users in an open system as the Tyolomnqa Estuary to harness knowledge and achieve their goals of using estuaries in a sustainable way.

This research only tackled an aspect of the problem. Similar studies should be done on other estuaries in the Eastern Cape in particular and South Africa in general in order to find out if the results would replicate the findings of this study. Other studies on the appropriate technology to facilitate knowledge distribution and sharing in underdeveloped communities should be initiated. Another possibility for research would be looking at incentives that can be used to encourage people to distribute and share knowledge on estuary management. Other areas of further research suggested by von Krogh and Roos (1996:228) are relevant to the Eastern Cape Estuaries. Taking into cognisance that "knowledge is and will be the most important source for building sustainable competitive advantage", von Krogh and Roos (1996:228) suggested some of the following areas:

I.What partners are attractive for an organisation's knowledge development?

2.How can knowledge be measured?

Lastly, the ability to identify suitable partners in knowledge development as well as measuring knowledge using defined indicators is likely to be key to addressing and reflecting on issues of knowledge management as they pertain to the sustainable use of estuaries.

\section{References}

Abell, A. \& Oxbrow, N. 200I. Competing with knowledge: the information professional in the knowledge management age. London: Library Association.

Alavi, M. \& Leidner, D. 1999. Knowledge management systems: issues, challenges and benefits. Communications of the Association for Information Systems, I (5): I-35.

Appiah, K. A. 199I. Is the post in postmodernism the post in postcolonial? Critical Inquiry, 17:336-357.

Awad, E. M. \& Ghaziri, H. M. 2004. Knowledge management. Upper Saddle River, NJ: Pearson Education.

Balcomb, A. 2000. The power of narrative: constituting reality through storytelling. In: Orality, memory and the past: listening to the voices of black clergy under colonialism and apartheid. Pietermaritzburg: Cluster Publications,49-62.

Barbour, R. S. \& Kitzinger, J. 1999. Developing focus group research: politics, theory and practice. London: Sage.

Blackler, F. 1995. Knowledge, knowledge work and organisations: an overview and interpretation. Organisational Studies, 16 (6): $1021-1046$.

Bless, C. \& Higson-Smith, C. 2000. Fundamentals of social research methods: an African perspective. $3^{\text {rd }}$ ed. Cape Town South Africa: Juta Publication.

Bloor, M., Frankland, J., Thomas, M. \& Robson, K. 200I. Focus groups in social research: introducing qualitative methods. London: Sage.

Botes, A. 2003. Validity, reliability and trustworthiness: to sum up. In: Rossouw, D (ed.) Intellectual tools: skills for the human sciences. $2^{\text {nd }}$ ed. Pretoria: Van Schaik, 176-184.

Breen, C. M., Adams, J., Batchelor, A., Cowley, P., Marneweck, G., McGwynne, L., McKenzie, M., Ngulube, P., Paterson, A., Sihlophe, N., Taljaard, S., Turpie, J., Uys, A., van Niekerk, L. \& Wood, A. 2004. Protocols contributing to the management of estuaries in South Africa, with a particular emphasis on the Eastern Cape Province. Pretoria: Water Research Commission. Cameron, J. 2000. Focussing on focus group. In: Hay, I (ed.) Qualitative research methods in human geography. Oxford: Oxford
University Press,83-102.

Chase, C. 2002. Turning knowledge into action at Heineken USA. Knowledge Management Review, 5(2):22-25.

Chase, R. L. 1997. The knowledge-based organization: an international survey. Journal of Knowledge Management, 1:38-49. Choo, C. W, Deltor, B \& Turnbull, D. 2000. Web work: information seeking and knowledge work on the World Wide Web.
Dordrecht: Kluwer Academic Publishers.

Co-Intelligent Institute. 2003. Defining collective intelligence. [Online]. http://www.co-intelligence.org/ Collectivelntelligence2.html\#definitions. Accessed I2/0I/2005. Davenport, T. H. \& Prusak, L. 1998. Working knowledge: how organizations manage what they know. Boston, MA: Harvard
Business School Press.

Denning, S. 2000. The springboard: how storytelling ignites action in knowledge-era organizations. Boston: Butterworth Heinemann. [Online]. http://www.stevedenning.com/knowledge_management.htm. Accessed 12/07/2002.

Donaldson, R. 2003. Using storytelling to connect stakeholders at English Nature. Knowledge Management Review, 6(3):3.

Environmental Protection Agency. 2003. About estuaries. [Online]. http://www.epa.gov/owow/estuaries/about l.htm. Accessed I8/ 06/2003.

Gamble, P. R. \& Blackwell, J. 200I. Knowledge management: a state of the art guide. London: Kogan Page. Gloet, M. 2002. Knowledge management audit: the role of managers in articulating and integrating quality practices. Managerial
Auditing Journal, I7(6):310-316.

Green, J. \& Hart, L. 1999. The impact of context on data. In: Barbour, R. S. \& Kitzinger, J (eds). Developing focus group research: politics, theory and practice. London: Sage,21-35. 
Hamilton, C. D. 2004. Come together: can we discover a depth of wisdom far beyond what is available to individuals alone? [Online]. http://www.wie.org/j25/collective.asp. Accessed 14/01/2005.

Hardy, B. 1975. Tellers and listeners: the narrative imagination. London: Athlone Press.

Harrison, T. D., Cooper, J. A. G. \& Ramm, A. E. L. 2000. Geomorphology, ichthyfauna, water quality and aesthetics of South African estuaries. Prepared by Division of Water, Environment and Forestry Technology for the Department of Environmental Affairs and Tourism. [Online]. http://www.environment.gov.za/soer/reports/ehi/ehi_chl.pdf. Accessed I4/08/2002.

Hawken, P., Ogilvy, J \& Schwartz, P. 1980. Seven tomorrows: towards a voluntary history. New York: Bantam Books.

Hellström, T. \& Husted, K. 2004. Mapping knowledge and intellectual capital in academic environments: a focus group study. Journal of Intellectual Capital, 5(I):165-180.

Hibbard, J. 1997. Knowledge management - knowing what we know. Information Week, (October 20).

Huseman, R. C. \& Goodman, J. P. 1999. Leading with knowledge: the nature of competition in the $21^{\text {st }}$ century. Thousand Oaks, CA: Sage.

Hutchins, E. 1995. Cognition in the wild. Cambridge: MIT Press.

Jordan, B. 1989. Cosmopolitical obstetrics: some insights from the training of traditional midwives. Social Science and Medicine, 28(9):925-944.

Kitzinger, J. 1994. Focus groups: method or madness. In: Boulton, M (ed.) Challenges and innovation: methodological advances in social research on HIVIAIDS, I59-175.

Knight, T. \& Howes, T. 2003. Knowledge management: a blueprint for delivery. Oxford: Butterworth-Heinemann.

Krueger, R. A. 1994. Focus groups: a practical guide for applied research. 2nd ed. Thousands Oaks, CA: Sage.

Levey, L. A. \& Young, S. (eds). 2002. Rowing upstream: snapshots of pioneers of the information age in Africa. Graighall, South Africa: Sharp Media.

Maponya, P. 2003. Development of a model for knowledge auditing in the Eastern Cape Estuaries with special reference to the Tyolomnqa Estuary. Masters thesis. Pietermaritzburg: University of Natal.

McClelland, S. B. 1994. Training needs assessment data-gathering methods: Part 3, focus groups. Journal of European Industrial Training, 18(3):29-32.

Merton, R. K., Fiske, M. \& Kendall, P. L. 1990. The focused interview: a manual of problems and procedures. 2nd ed. London: Collier Macmillan.

Morgan, D. L. 1988. Focus groups as qualitative research. London: Sage.

Mosia, L. N. 2002. Knowledge sharing and distribution in an open system: a case study of the Eastern Cape Estuaries Management Programme. Masters thesis. Pietermaritzburg: University of Natal.

Mosia, L. N. \& Ngulube, P. 2003. Knowledge sharing and distribution for the sustainable utilization of estuaries in the Eastern Cape. Paper prepared for the International Conference on Collaboration and sharing of knowledge held in Pretoria on 30-31 July 2003. [Online]. http://www.unisa.co.za/contents/faculties/ humanities/docs/. Accessed 10//2/2003.

Mouton, J. 200I. How to succeed in your masters and doctoral studies: a South African guide and resource book. Pretoria: van Shaik Publishers.

Newell, S., Robertson, M., Scarbrough, H. \& Swan, J. 2002. Managing knowledge work. New York, NY: Palgrave.

Noubel, J. 2003. Collective intelligence: the invisible revolution. [Online]. http://www.noubel.com/mt/weblogs/ci/archives/ 000102.php. Accessed 10/01/2005.

Philp, R. 2003. Curiosity cures the knowledge gap. Sunday Times (January 19).

Probst, G., Raub, S. \& Romhardt, K. 2000. Managing knowledge: building blocks for success. Chichester: John Wiley.

Robertson, T. 2003. Knowledge is not powerful until it is shared with others. Columbus Federal Voice Newspaper, June I8: 9-II.

Roth, W-M. 1999. Authentic school science: intellectual traditions. In: McCormick, R \& Paechter, C (eds). Learning and knowledge. London: Paul Chapman Publishing, 6-20.

Rowley, J. 2002. Using case studies in research. Managing Research News 25(I):16-27.

Sallis, E. \& Jones, G. 2002. Knowledge management in education: enhancing learning and education. London: Kogan Page.

Skyrme, D. \& Amidon, D. 1997. The knowledge agenda. Journal of Knowledge Management, I(I):6-14.

Snowden, D. 2002. Complex acts of knowing: paradox and descriptive self-awareness. Journal of Knowledge Management, 6(2): $1-14$.

Stewart, D. W. \& Shamdasani, P. N. 1990. Focus groups: theory and practice. Newbury Park: Sage.

Storck, J. \& Hill, P. A. 2000. Knowledge diffusion through strategic communities. Sloan Management Review, 4I (2):63-74.

Todd, R. J. 1999. Knowledge management: utilising the knowledge capital of a learning community. Access, I3(3): I I-I4.

Von Krogh, G. \& Roos, J. 1996. Afterword: an agenda for practice and future research. In: Von Krogh, G. \& Roos, J. (eds). Managing knowledge: perspectives on cooperation and competition. London: Sage, 226-229.

Von Seggern, M. \& Young, N. J. 2003. The focus group method in libraries: issues relating to process and data analysis. Reference Services Review, 3 I (3): 272-284.

Webb, S. 1998. Knowledge management: linchpin of change-some practical guidelines. London: Aslib.

Weick, K. 1979. The social psychology of organising. Reading, MASS: Addison-Wesley.

Wenger, E. 1998. Communities of practice: learning, meaning and identity. Cambridge: Cambridge.

Wiig, K. M. 1999. Knowledge management: an emerging discipline rooted in history. [Online]. http:// www.knowledgeresearch.com/dowloads. Accessed 15/04/2002.

Yin, R. K. 1994. Case study research, design and methods. 2nd ed. Newbury Park: Sage Publications. 